\title{
Penetapan Kembali Desa Warunggahan sebagai Sima di Tuban Jawa Timur
}

\author{
Armyatul Khabibah ${ }^{*}$, I Gst Ngurah Tara Wiguna \\ Prodi Arkeologi, Fakultas Ilmu Budaya, Universitas Udayana \\ [armyelzahra96@gmail.com] \\ Banyuwangi, Jawa Timur, Indonesia \\ *Corresponding Author
}

\begin{abstract}
Inscriptions as textual media and material products of past human activities are included in the category of artifacts. Most of the inscriptions issued by Sri Maharaja Nararyya Sanggramawijaya contained the stipulation of sima. Reestablishment of Warunggahan village as a gift of sima by Sri Maharaja Nararyya Sanggramawijaya is a form of retribution given by Krtanagara to Paduka Mpungku Sri Buddhaketu for his services while accompanying Krtanagara to become king in Singhasari. The reestablishment of sima in Warunggahan village gave privileges to residents of the sima region, one of which was tax deduction. The tax allocation that was supposed to be submitted to the kingdom was used to maintain the dharmma (sacred building) periodically and the cost of building maintenance funding could be guaranteed.
\end{abstract}

Keywords: sima, reestablishment, Sri Maharaja Nararrya Sanggramawijaya, Paduka Mpungku Sri Buddhaketu

\begin{abstract}
Abstrak
Prasasti sebagai media tekstual dan produk bendawi dari aktivitas manusia pada masa lampau dan masuk dalam kategori artefak. Sebagian besar prasasti Kerajaan Majapahit yang dikeluarkan Sri Maharaja Nararrya Sanggramawijaya berisi mengenai penetapan sima. Penetapan kembali Desa Warungahan sebagai anugrah sima oleh Sri Maharaja Nararrya Sanggramawijaya merupakan bentuk balas jasa yang diberikan Krtanagara kepada Paduka Mpungku Sri Buddhaketu atas jasajasanya selama mendampingi Krtanaga menjadi raja di Singhasari. Penetapan kembali sima di Desa Warungahan memberikan hak istimewa kepada penduduk wilayah sima, salah satunya pengurangan pajak. Alokasi pajak yang seharusnya diserahkan kepada kerajaan digunakan untuk memelihara dharmma (bangunan suci) secara periodik sehingga keperluan pembiayaan pemeliharaan bangunan dapat terjamin.
\end{abstract}

Kata Kunci: sima, penetapan kembali, Sri Maharaja Nararrya Sanggramawijaya, Paduka Mpungku Sri Buddhaketu

\section{PENDAHULUAN}

Zaman sejarah di Indonesia dipengaruhi oleh kebudayaan HinduIndia yang masuk ke Nusantara. Bukti dari zaman sejarah Indonesia dapat dilihat dari beberapa prasasti tertua dengan aksara Pallawa dan bahasa Sansekerta yang ditemukan pada abad IV Masehi, seperti prasasti Yupa di Kutai, Kalimantan Timur dari Kerajaan Kutai dan prasasti-prasasti peninggalan Raja 
Purnavarman abad IV-V Masehi dari Kerajaan Tarumanegara, Jawa Barat.

Prasasti dapat diartikan sebagai salah satu artefak berbentuk keputusan resmi yang dikeluarkan oleh penguasa atau raja yang berisi pengumuman, peraturan, dan/atau perintah. Prasasti memuat sajak atau pujian untuk memuji raja, atas karunia yang diberikan kepada bawahannya, agar hak tersebut sah dan dapat dipertahankan secara yuridis. Prasasti dirumuskan dalam bahasa resmi hukum dengan gaya hukum tertentu. Prasasti yang dikeluarkan oleh raja atau ratu sangat penting artinya bagi desa atau pihak penerima prasasti, karena di dalamnya diatur kewenangan, kewajiban, serta tugas pihak penerima prasasti yang patut dilaksanakan oleh masyarakat. Hampir seluruh prasasti Jawa kuno yang ditemukan berisi tentang penetapan sima yang diberikan kepada seseorang, baik yang berjasa kepada raja maupun sima untuk menunjang bangunan keagamaan (Darmosoetopo 2003: 11). Peninggalan prasasti terbanyak ditemukan di Pulau Jawa. Salah satunya berada di Tuban, Jawa Timur yaitu prasasti Warungahan yang kemungkinan berasal dari masa Kerajaan Majapahit Awal.

Berdirinya Kerajaan Majapahit tidak lepas dari nama Kerajaan Singhasari. Para pemimpin Kerajaan Singhasari hingga Kerajaan Majapahit masuk dalam susunan Dinasti Rajasa (Rājasawañśa). Śrī Mahārāja Narārrya Sangramawijaya atau Raden Wijaya, pendiri Majapahit termasuk dalam Dinasti Rajasa (Rājasawayśa), ia adalah anak dari Dyah Lěmbu Tal, cucu Mahișa Campaka atau Narasinghamuri, secara genealogi masih keponakan Kṛtanagara, sekaligus menantu Kṛtanagara. Śrī Mahārāja Narārrya Sañgramawijaya dikawinkan dengan keempat putri Kṛtanagara. Berikut adalah silsilah raja Kerajaan Singhasari.

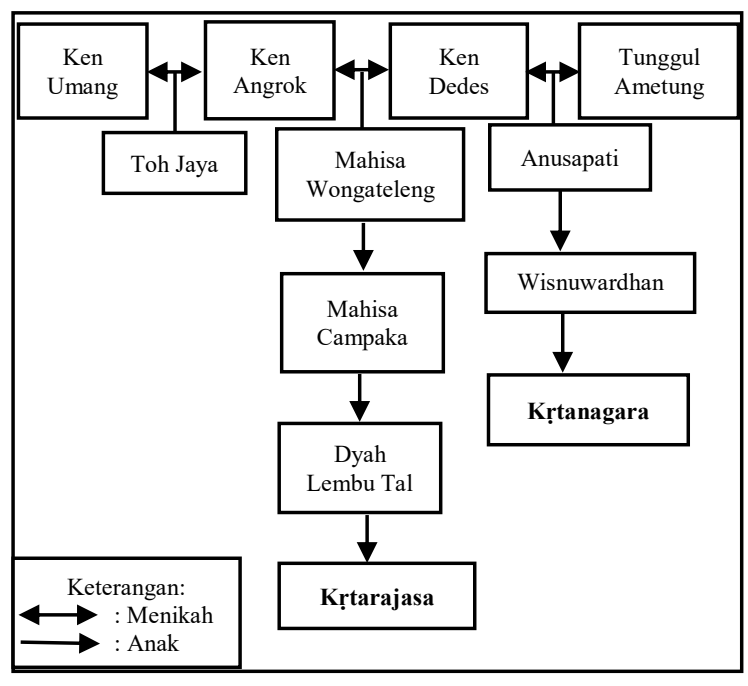

Selama memerintah Singhasari Krtanagara menorehkan banyak prestasi. Salah satunya, dalam bidang militer, Kṛtanagara mampu menaklukkan beberapa pulau, hal ini ditasbihkan dalam arca Camundi. Kemunduran Singhasari berasal dari serangan Jayakatwang yang menyebabkan terbunuhnya Krtanagara. Hal ini didasarkan pada prasasti Gajah Mada yang berisi tentang peringatan pembuatan bangunan caitya oleh Rakryyan Mapatih Mpu Mada yang dipersembahkan untuk para BrahmanaSiwa dan sogata yang ikut gugur bersama Kṛtanagara (Poesponegoro. 2009:419).

Pada tahun 1191 Śaka/1269 Masehi, Kṛtanagara mengeluarkan prasasti Sarwwadharmma ditemukan di Penampihan, lereng Gunung Wilis, Kediri. Prasasti ini menerangkan bahwa penduduk daerah Sarwwadharmma dengan perantara sañ Rāmapati bersama rakryyān Apatih dan san Dharmmādhyakṣa di Kaśaiwan Sang Apañji Tanutama, datang menghadap raja memohon agar daerah mereka lepas dari wilayah thānibala dan kembali menjadi daerah swatantra. Menurut keterangan penduduk Sarwwadharma, dahulu semasa pemerintahan Wiṣnuwarddhana daerah ini telah ditetapkan menjadi daerah swatantra lpas dari wilayah thānibala, yaitu ketika Pañji Pati-pati menjabat dharmmādikarana. 
Śr̄̄ Mahārāja Narārrya Sangramawijaya atau Raden Wijaya atau Krțarājasa Jayawarddhana, keturunan Dinasti Rajasa (Rājasawayśa), naik tahta Majapahit (wilmatikta) pada tahun 1215 Śaka/1293 Masehi, setelah berhasil mengalahkan kekuatan Jayakatwang (Daha) dengan bantuan bala tentara Khubilai Khan. Kisah penyerangan ini terdapat dalam prasasti Kudadu 1216 Śaka/1294 Masehi. Prasasti Kudadu dikeluarkan oleh Kṛtarājasa Jayawarddhana, berisi mengenai penetapan desa Kudadu menjadi daerah swatantra yang diberikan kepada para pejabat desa (rāma). Alasan daerah Kudadu ditetapkan menjadi daerah swatantra karena para rāma telah berjasa dalam memberikan perlindungan serta bantuan pada saat raja Kěrtarājasa Jayawarddhana/Narārrya

Sangramawijaya saat dikejar oleh pasukan Jayakatwang.

Selang beberapa waktu, setelah penobatan Śr̄ Mahārāja Narārrya Sangramawijaya sebagai raja Majapahit, pasukan yang dahulu diutus oleh Kṛtanagara ke nusāntara kembali dengan membawa hasil yang gemilang, yaitu takluknya beberapa raja di nusāntara disertai pemberian upeti. Pengikut Śrī Mahārāja Narārrya Sañgramawijaya yang setia dan berjasa dalam perjuangan mendirikan Majapahit, diberikan kesempatan untuk menikmati hasil perjuangan dan beberapa diangkat sebagai pejabat tinggi dalam struktur pemerintahan, maupun pemberian daerah swatantra.

Disebutkan pada bagian awal bahwa Prasasti Warungahan merupakan salah satu prasasti yang berasal dari Majapahit. Prasasti tersebut menyebutkan bahwa anak keturunan serta saudara Pāduka Mpunkku Śrī Buddhaketu memohon kepada Śrī Mahārāja Narārrya Sangramawijaya agar Desa Warungahan ditetapkan kembali sebagai wilayah anugerah sima. Hal ini dibahas lebih dalam sebuah penelitian yang berjudul "Penetapan Kembali Desa Warungahan Sebagai Sima di Tuban, Jawa Timur"

Berdasarkan uraian yang telah dipaparkan di atas, maka ada dua permasalahan yang akan dibahas, yakni: Mengapa Desa Warungahan ditetapkan kembali sebagai anugerah sìma oleh Śrī Mahārāja Narārrya Sañgramawijaya?, Bagaimana fungsi prasasti Warungahan dalam kehidupan masyarakat kuno Desa Warungahan?

Adapun tujuan penelitian ini, yaitu untuk menjawab permasalahan yang telah dirumuskan secara terperinci sebagai berikut, a) Mengetahui sebab penetapan kembali Desa Warunggahan sebagai anugerah sìma oleh Śrī Mahārāja Narārrya Sañgramawijaya. b) Mengetahui fungsi prasasti Warungahan dalam kehidupan masyarakat kuno Desa Warungahan

\section{METODE}

Penelitian ini bersifat kualitatif. Penggunaan metode kualitatif dilakukan untuk memanfaatkan data tertulis serta objek yang diamati melalui interprestasi. Hasil penelitian akan disajikan dalam bentuk penjelasan dan pendeskripsian. Salah satu analisis yang digunakan dalam penelitian ini adalah analisis kontekstual. Analisis kontektual digunakan dalam penelitian ini, yaitu mencari korelasi antara data teks yang menghubungkan antara data primer berupa yang telah ditranskrip kedalam tulisan latin dengan data sekunder berupa prasasti, kesusastraan dan objek kajian lain sehingga diperoleh sumber data yang beragam namun saling berkaitan.

Penelitian ini dilakukan di Dusun Trowulan, Desa Bektiharjo, Kecamatan Semanding, Kabupaten Tuban, Jawa Timur. Lokasi ini dipilih karena di daerah inilah ditemukannya prasasti Warungahan, yang berisikan mengenai penetapan kembali Desa Warungahan sebagai anugerah simma abad XIV Masehi 
yang dikeluarkan oleh Śrī Mahārāja Narārrya Sañgramawijaya.

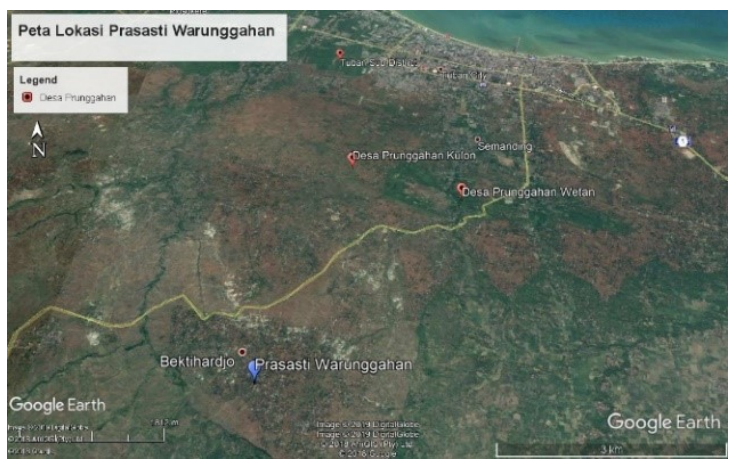

Peta Lokasi Penelitian

(Sumber: Diolah dari Digital Google Earth)

\section{HASIL DAN PEMBAHASAN}

Penerbitan prasasti oleh raja atau ratu pada mulanya sebagai bentuk peringatan atas suatu peristiwa penting yang kemudian dipahatkan pada bahan yang keras, seperti batu, logam atau kayu. Sejalan dengan perkembangan zaman dan kemampuan masyarakat, maka perkembangan isi dalam prasasti pun berkembang, bukan sebagai bentuk peringatan tetapi digunakan sebagai dokumen yang memiliki kekuatan hukum (Suhadi, 1993:238). Prasasti Warungahan ditemukan di Dusun Trowulan, Desa Bektiharjo, Kecamatan Semanding, Kabupaten Tuban, Jawa Timur. Prasasti ini merupakan sumber tertulis yang terbuat dari tembaga, yang digoreskan pada sisi lempeng prasasti. Isi dari prasasti ini cukup lengkap terdiri 14 lempeng dengan 148 baris.

Prasasti Warungahan menggunakan aksara Jawa Kuno dan bahasa bilingual (Sansekerta dan Jawa Kuno). Dikeluarkan oleh Śrī Mahārāja Narārrya Sangramawijaya pada tahun 1227 Śaka/1305 Masehi. Penanggalan terdapat pada lempeng I.b.1\&3,

"swasti śaka warșâtīta, 1227, weśaka māsa, tīthi pañcadaśi krșnapakșa, pā, $w a, \quad c a, \ldots$ irika diwaśanyājñ̄a śr mahārāja narāryya saìgrāmawijaya, rājasawaìśa śürasinhā bhuwaneka wikrama..."

Terjemahan:

"selamat tahun 1227 śaka, bulan April, lima belas hari paro gelap, pāniron, wage, caniswara... itulah saat turunnya perintah dari śri mahārāja narāryya saìgrāmawijaya, rājasawañśa śūrasinhā bhuwaneka wikrama..."

\section{Penetapan Kembali Desa Warungahan sebagai Sïma}

Penetapan suatu wilayah menjadi sìma merupakan salah satu bentuk anugerah istimewa yang dikeluarkan raja kepada pengikutnya atau penduduk diluar garis keturunan kerajaan. Baik dalam tujuan spiritual, bentuk balas jasa atas kebaktian penduduk tersebut maupun pengukuhan (penetapan kembali). Pengukuhan kembali diberlakukan untuk desa sima yang sudah dimiliki dari raja sebelumnya dan penduduk desa tersebut menunjukkan kesetiaan yang besar kepada yang memerintah selanjutnya.

Kṛtanāgara ketika masih bertahta menjadi seorang raja, menghadiahkan desa sìma bernama Desa Warungahan kepada pāduka mpunkku śrī buddhaketu sebagai tanda jasa atas kebaktiannya kepada raja. Hingga masa keruntuhan pemerintahan dan Kerajaan Singasari tiba di tangan Jayakatwang. Kemudian Śrī Mahārāja Narārrya Sañgramawijaya atau Raden Wijaya, menantu sekaligus keponakan Krtanāgara merebut kembali dengan mendirikkan kerajaan baru bernama Majapahit.

Prasasti Warungahan menyebutkan nama tokoh Pāduka Mpuñku Śri Buddhaketu yang merupakan penerima hak atas simma di Warungahan. Namun, bukti kepemilikan prasasti Warungahan (pemberian Kṛtanāgara) telah hilang saat terjadinya gempa. Anak keturanan dan kerabat Pāduka Mpuñku Śrī Buddhaketu memohon kepada Śrī Mahārāja Narārrya Sañgramawijaya agar Desa 
Warungahan ditetapkan kembali hak kepemilikannya. Pengajuan tersebut terdapat dalam prasasti Warungahan lempeng III.a.2-4,

“...pāduka mpuñku śrī buddhaketu mway samasānak samudaya, makamukhya dañācāryya candra nātha, datěn $i$ sanmukha say wirapatī, umajarakěn ri hilay niy praśāsty anugraha bhațāra śrī krtanagara...

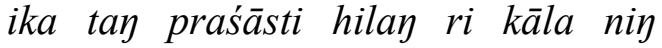
bhūmi kampa..."

Terjemahan:

“...keluarga pāduka mpuñku śrī buddhaketu, salah satu di ataranya bernama dañācāryya candra nātha, datang menghadap say wirapatī menyampaikan hilangnya prasasti anugerah bhațāra śri krtanagara...prasasti itu hilang saat gempa bumi..."

Patut diduga bahwa tokoh Pāduka Mpunku Śri Buddhaketu adalah seorang bangsawan sepuh terhormat yang memilih jalan hidup sebagai pendeta (Sambodo, 2018:33). Dijelaskan pula dalam penafsiran Prasasti Warungahan adanya penghargaan kepada Pāduka Mpunkku Śr̄ Buddhaketu yang telah menemani Kṛtanāgara dalam menjaga kerajaan Singhasari, serta menemani Kṛtanāga saat bersemedi. Tertera pada lempeng V.b.4-5.

“...makanimitta go" ny adhimukti bhațāra śrī krtanagara, ri pāduka mpuñku śrī buddhaketu, gati nirān pinaka roway de bhațāra śrī krtanagara manalocitta kabhūmirakșakān, muwaḥ sira pinaka roway de bhațāra śri krtanagarā nabhyasāinaccane bhațāra śrī wairocana jagaddhita, makādī swarggā..."

Terjemahan:

“...sebab turunnya perintah bhațāra śri krtanagara adalah sebagai bentuk hadiah atas kebaktian pāduka mpunkku śri buddhaketu kepada raja, pāduka mpuñku śrī buddhaketu merupakan kawan dari bhațāra śrī krtanagara saat mawas diri (menjaga kerajaan), ia ikut

menemani bhațāra śrī krtanagara mendekatkan diri dan memuja bhațāra śrī wairocana memohon kesejahteraan dunia dan surga..."

Dengan alasan tersebut ahli waris serta sanak saudaura Pāduka Mpuñku Śri Buddhaketu melalui Say Wīrapati mengajukan penetapan kembali Desa Warungahan kepada Śrī Mahārāja Narārrya Sangramawijaya.

Alasan tersebut disetujui oleh Śrī Mahārāja Narārrya Sañgramawijaya, sehingga prasasti Warungahan diterbitkan untuk menetapkan kembali Desa Warungahan sebagai daerah sima. Seperti dapat dibaca pada lempeng IV.b.4-5.

“...kapan்kwa de wka pāduka mpuñku buddhaketu mway samasānak $i$ warungahan. katamwa kalilirana deni santana pratisantana pāduka mpun்ku Śri buddhaketu mway samasānak $i$ warungahan..."

Terjemahan:

“...untuk dipangku (dibawa) oleh anak keturunan Pāduka Mpuñku Buddhaketu serta saudaranya di Warungahan, karena telah diterima kembali oleh anak keturunan Pāduka Mpuñku Śri Buddhaketu serta saudaranya di Warungahan..."

\section{Fungsi Prasasti Warungahan dalam Kehidupan Masyarakat Kuno Desa Warungahan}

Perubahan status tanah dari kedudukan sebagai tanah yang biasa menjadi tanah anugerah sima juga membawa perubahan garis komando, pemerintah pusat yang dapat diberikan langsung kepada kepala tanah sima tanpa melalui pejabat-pejabat di bawah raja. Pembagian wilayah administratif akan menentukan arus perintah, karena dalam situasi yang baru, para rāma dilepaskan dari jabatannya, karena kepala sima 
diawasi langsung oleh raja atau pemerintah pusat.

Ada beberapa kebijakan istimewa yang diberikan kepada kepala sima, misalnya pengurangan pajak bagi desa sima, seperti pembatasan atau pengaturan sendiri pajak usaha, pembagian hasil pajak bumi dan usaha kerajinan dan perdagangan. Alokasi pungutan pajak yang harusnya disetorkan ke kerajaan menjadi hak milik bangunan suci yang ada di wilayah simma. Pembahasan ini tertera pada prasasti Warungahan,

Pengaturan pajak usaha kerajinan, lempeng X.b.2-4,

“...kuněy ikay miśra mañěmbul, mañaywriy, mañgumaray, amdèl, amahañan, añarub, an்ubar, anula

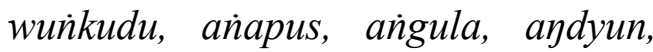

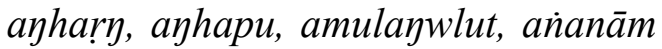
anām, agawai pajěywlū, mopiḥ, makațay nipah, runkki, magawey kisī, amubut, akalākalā manuk, amisandung manuk, añjariy, anañkéb..."

Terjemahan:

“...adapun jenis pajak kerajinan, berupa pewarnna hitam, mañaywriy, mañgumaray, amděl, amahañan, añarub, an்bar, pewarna merah, tali jaring, gula sirup, periuk belanga, arang, kapur, amulaywlut, anyaman, payung tiga warna (untuk upacara kerajaan), mopih, bunga bungur (?), sarung keris, tas anyaman (?), bubut (alat melicinkan besi/kayu), jebakan burung, jeratan burung, jarring ikan, jangkar (?), anaway, amasay wlah, perangkap..."

Pengaturan pajak usaha jual beli ternak, lempeng XII.a.3-4,

"...yan pañulay kbo prana 20 kbwanya, yan pañulay sapi prana 40 sapiyanya, yan panula wọ prana 80 wdusnya, yan pañulay celey prana, sawuragan celenanya..."

Terjemahan:

“... batas jual beli kerbau sebanyak 20

ekor, batas jual beli sapi sebanyak 40 ekor, batas jual beli kambing sebanyak 80 ekor, dan batas jual beli babi hutan sebanyak sawuragan celenanya..."

Pengaturan pajak usaha perdagangan, lempeng XII.a.5-7,

“... kuněñ hinan $i$ bhaṇ̣an yān ni pikul pikulan, kadyanga niy dodot, lawai, kapas, bsar, kasumba, wuykudu, day, dhulay, jadhi, ketekete, paliwtan, wsi, pamaja, timah, kaniśa, wuyah, kamal, lina, lurunan, klětik, gula, kalapa, wwawwahan..."

Terjemahan:

"...adapun jenis barang dagang yang dipikul, seperti kain panjang, benang, kapas, beras, pewarna kain merah (?), bejana, tempat saji atau makanan, buah temu (?), bunga pudak, penanak nasi, besi, bahan pewarna (?), timah, perunggu, garam, asam, minyak, lurunan, minyak, gula, kelapa, buahbuahan..."

Para penduduk wilayah anugerah sima juga diberikan kebebasan untuk makan rājamānisa. Disebutkan dalam prasasti Warungahan lempeng XI.b.3-4,

“...mway wnañ amañana rāja mañśa,

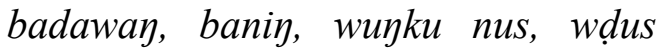

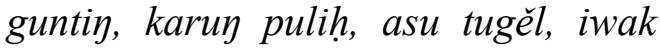
taluwah..."

Terjemahan:

"...diizinkan memakan rāja màiśa, diantaranya penyu, kura-kura, wuๆku nus, kambing yang belum berekor, babi hutan, anjing kebiri, ikan taluwah..."

Diizinkan pula dalam memungut serta mengatur denda dari sukhaduhkha, terdapat dalam lempeng X.a.4-6 hingga lempeng X.b.1,

“...mankana tekay sukhaduhkha, kadyangani mayay tan pawwah walu rumāmbat in natar, wipati wankkai kabunan, rāh kasawur i natar, kadal mati riy hawan, sahasa, wākcāpala, hastacāpāla, duhilatèn hidu kasirat, amijilakěn wuryyanin kikir, mamuk mamuppay, ludan, tūtan, těṇdas nị 
mās, daṇda kudaṇḍ, añśapratyainśa, mandihalādi ..."

Terjemahan:

“...pengaturan sukhaduhkha (denda), seperti bunga mayang yang tak berbuah, batang labu yang menjalar di halaman, kematian, bangkai yang terkena embun, darah yang tercecer di halaman, kadal yang mati di halaman, menganiaya, menghina, memukul dengan tangan (berkelahi), meludah, mengancam dengan senjata tajam, mengamuk, memperkosa, menyerang, tūtan, menghina, memukul dengan tongkat, à́śapratyaíśa, meracun..."

Hak istimewa lainnya dalam hal memasang payung tiga warna, memainkan alat gelang keroncong atau lagu gending, menghias rumah dengan bambu, terdapat dalam prasasti Warungahan lempeng XI.a.5,

“...amaguta pajo" tigawarnna, an்ykunacuriy rahina wri...”

Terjemahan:

"...memasang payung tiga warna, memainkan alat musik gelang keroncong (lagu gending)..."

Pengaturan berbagai keputusan yang diberikan oleh raja kepada daerah sima dikuatkan dengan sapatha yang berisi mengenai berbagai kutukan agar para penduduk sima tidak melanggar aturan. Sapatha difungsikan pula sebagai bentuk kuasa seorang raja, sehingga penduduk wilayah sima akan tunduk atau patuh (Ardika, dkk. 2018). Sapatha pada prasasti Warungahan terdapat pada lempeng XIV.b.1-7,

"...yan aparaparan humalintay rin tgal sahutěn denin ulā manḍi, yan paren alas, dmak niך moy, mañ alañka hana mimaysārit ni wanaspati, yan haliwat ri wwa ya göy, sahutěn denin wuhaya, mumul, tuwiran, yan haliwat ya ring ratā kasaṇduney ruyunawuk kasopa wulañuna, kuney pwa yan hudan adrss sāmběrn denī glap, humunigu pwa ya rī sthānanya, katibana ta ya bajrāgni tanpa warșa, himutěn gsěnana de say hyan் agni saha drwyanya tan panolih ariwuntat, taruy ri paña dgan, tāmpyal, ri kawanuwalītnénan, tutuh tundunya, blah kapalanya, cucup utěknya, sbit wtīnya, rantan ususnya wtwakěn dalmanya, duduk atinya, painan daginnya, inum rāhnnya, athěr pěpědakěn weh aprāla ntika, arạ̣ ta kita kamu hyay suwuk lor, kidul, kulwan, wetan byěnakěn rin ākāśa sulā."

Terjemahan:

“...bagi pelanggar keputusan raja, apabila ia melintasi kebun akan digigit ular berbisa, apabila melintas di hutan, ada harimau yang siap menerkam dan ular besar di dalam wanaspati [hutan berhantu], orang yang melintasi air dengan suara, ia akan diterkam buaya, hiu, ular laut (?) besar, apabila berjalan atau melintasi jalan atau tanah yang rata akan terbentur ruyunawuk hingga kehilangan ingatan, jika berasa dalam situasi hujan yang sangat lebat saat malam (gelap gulita), dan berlindung di kediaman, ia akan terkena kilat (petir) tanpa hujan, api akan membakar semua miliknya dari depan hingga yang ada dibelakang, jika ia melawan kawanuwalìtnènan, cerca puncaknya (kepala), potong kepalanya, teguk otaknya, lukai hatinya, urai ususnya hingga bagian dalam, congkel hatinya, makan dagingnya, ambil nyawanya, jemur badannya hingga rusak (hancur) hingga bagian dalam..."

\section{SIMPULAN}

Berdasarkan pembahasan dapat disimpulkan bahwa, Kṛtanāgara ketika masih bertahta menjadi seorang raja, menghadiahkan desa simma bernama Desa Warungahan kepada pāduka mpunkku śri buddhaketu sebagai tanda jasa atas kebaktiannya kepada raja. Hingga masa keruntuhan pemerintahan dan Kerajaan Singasari tiba di tangan Jayakatwang. 
Kemudian Śr̄̄ Mahārāja Narārrya Sangramawijaya atau Raden Wijaya, menantu sekaligus keponakan Kṛtanāgara merebut kembali dengan mendirikkan kerajaan baru bernama Majapahit. Alasan Śrī Mahārāja Narārrya Sàngramawijaya penetapkan kembali Desa Warungahan sebagai daerah sima, atas permintaan ahli waris pāduka mpunkku śrí buddhaketu dikarenakan prasasti yang terdahulu telah hilang saat bhümi kampa (gempa bumi). Dari prasasti Warungahan dapat diketahui bahwa penetapan kembali Desa Warungahan sebagai sima bersifat balas jasa. Dijelaskan dalam penafsiran prasasti adanya penghargaan kepada pāduka mpuñku śrì buddhaketu yang telah menemani Kṛtanāgara dalam menjaga kerajaan Singhasari, serta menemani Kṛtanāga saat bersemedi. Pengajuan dari ahli waris melalui Say Wīrapati yang kemudian disetujui oleh Śrī Mahārāja Narārrya Sañgramawijaya, dimana didalamnya terdapat ketentuan-ketentuan serta kewajiban-kewajiban yang harus dipenuhi oleh penduduk Desa Warungahan.

Penetapan kembali Desa Warungahan menjadi daerah anugerah sima membawa perubahan yang menggembirakan bagi penduduknya. Wilayah anugerah sima yang ditetapkan tidak dapat dimasuki oleh pemungut pajak say mahāmantri katriṇi, nayaka, pratyaya, pighe wahuta.

Wilayah sima mendapatkan kebijakan istimewa yang diberikan kepada kepala sima, seperti pengurangan pajak bagi desa sìma, pembatasan atau pengaturan sendiri pajak usaha, pembagian hasil pajak bumi dan usaha kerajinan dan perdagangan. Alokasi pungutan pajak yang harusnya disetorkan ke kerajaan menjadi hak milik bangunan suci yang ada di wilayah sima.

\section{SARAN}

Penelitian terhadap prasasti Indonesia perlu ditingkatkan, mengingat dari prasasti didapatkan banyak informasi tentang kehidupan masyarakat masa lalu yang masih relevan dengan keadaan masyarakat masa sekarang. Proses pengerjaan terkait pengumpulan datadata pustaka yang bersangkutan mengenai Prasasti Warungahan sangat sedikit, sehingga perlu adanya penelitian lebih lanjut dan dalam mengenai prasasti Warungahan yang dikeluarkan oleh $S$ ri Mahārāja Narārrya Sañgramawijaya ini.

\section{REFERENSI}

Ardika, I Wayan, dkk. 2018. Sapatha dalam Relasi Kuasa dan Pendisiplinan pada Masyarakat Bali Kuno Abad IX-XIV Masehi. Berkala Arkeologi Vol.38 No.1 Edisi Mei 2018. Hal 11-14.

Ardiyansah, Ardiyan dan Mahardhika. Lingkungan dan Pemukiman Zaman Kerajaan Majapahit dalam CGI. Humaniora Vol.1 No.2 Edisi Oktober 2010. Hal 728-736.

Atmodjo. Sukarto.K. 1982. Prasasti Singkat Dari Empat Buah Makam Islam dan Sebuah Gua di Daerah Tuban. Berkala Arkeologi Vol.3 No.1.

Casparis, J. 1985. Penyelidikan Prasasti. Amerta, Jurnal Penelitian dan Pengembangan Arkeologi Vol.1. Hal 25-29.

Darmosoetopo, Riboet. 1995. Dampak Kutukan dan Denda Terhadap Penetapan Sima pada Masyarakat Jawa Kuno. AHPA, Proyek Penelitian Purbakala Jakarta. Hal 17-22.

Darmosoetopo, Riboet. 2003. Sima dan Bangunan Keagamaan di Jawa Abad IX-X. Yogyakarta: Prana Pena. 
Dwiyanto, Djoko. 1998. Manfaat Prasasti Bagi Penelitian Sejarah Lokal. Berkala Arkeologi Tahun XVIII-Edisi Khusus Balai Arkeologi Yogyakarta. Yogyakarta: Balai Arkeologi.

Lelono, T.M. Hari. 2012. Jenis-Jenis Kejahatan Berdasarkan Naskah Dan Relief Pada Masa Jawa Kuna. Forum Arkeologi Vol. 25 No. 2 Edisi Agustus 2012. Hal 171183.

Nastiti, Titi Surti. 1982. Masalah Hak Milik atas Tanah Abad 9 dan 10 Masehi. Amerta, Jurnal Penelitian dan Pengembangan Arkeologi Vol.6. Hal 7-12.

Poesponegoro, Marwati D dan Notosusanto, Nugroho (ed). 2009. Sejarah Nasional Indonesia II. Jakarta: Balai Pustaka.

Sambodo, Goenawan. A. 2018. Prasasti Warungahan Sebuah Data Baru dari Masa Awal Majapahit. Amerta, Jurnal Penelitian dan Pengembangan Arkeologi Vol. 36 No.1 Edisi Juni 2018. Hal 1-66.

Santiko, Hariani. 2012. Agama dan Pendidikan pada Masa Majapahit. Amerta, Jurnal Penelitian dan Pengembangan Arkeologi Vol. 30 No.2 Edisi Desember 2012. Hal 123-133.

Satari, Sri Soejatmi. 2009. Upacara Weda di Jawa Timur: Telaah Baru Prasasti Dinoyo. Amerta, Jurnal Penelitian dan Pengembangan Arkeologi Vol.27 No.1. Hal 34-43.

Suarbhawa, I Gusti Made. 2000. Teknik Analisis Prasasti. Forum Arkeologi
II. Balai Arkeologi Denpasar Vol.1 Edisi November. Hal: 135 - 147.

Suhadi, Machi. 1993. Tanah Sima dalam Masyarakat Majapahit. Jakarta: Program Pascasarjana, Universitas Indonesia. Disertasi Tidak Diterbitkan.

Suhadi, Machi. 1984. Beberapa Jenis Pajak pada Jaman Majapahit. REHPA II, Cisarua.

Sumarno, Aris, dkk. 2007. Mutiaramutiara Majapahit. Jakarta: Departemen Kebudayaan dan Pariwisata.

Sumerata, I Waya. 2016. Makna Sapatha Dalam Prasasti Sukawana. Forum Arkeologi Vol. 29 Edisi No.3 November 2016. Hal 137-146.

Umar, Kamahi. 2017. Teori Kekuasaan Michel Foucault: Tantangan bagi Sosiologi Politik. Jurnal AlKhitabah, Vol. III, No. 1, Juni 2017 : $117-133$.

Wibowo. 1977. Riwayat Penyelidikan Prasasti di Indonesia. 50 Tahun Lembaga Purbakala dan Peninggalan Nasional 1913-1963. Jakarta: Depdikbud.

Zoetmulder, P.J. 1995. Kamus Jawa Kuna Indonesia. IV. Jakarta: PT Gramedia Pustaka Utama. 